\title{
Persistence and fate of highly soluble pharmaceutical products in various types of municipal wastewater treatment plants
}

\author{
C. Gagnon \& A. Lajeunesse \\ Science \& Technology Branch, Environment Canada, Canada
}

\begin{abstract}
Municipal effluents are important source of contaminants including many socalled Pharmaceutical and Personal Care Products (PPCPs) substances, whose potential impacts on the receiving environment are poorly understood. New emerging substances, in the form of pharmaceutical drugs like antibiotics, antiinflammatory, and anti-convulsive, are now being frequently measured in these wastewaters. While PPCPs substances undergo major transformation at the treatment plant and again in the receiving waters, their bioavailability and toxicity may be modified considerably. The influence of different wastewater treatment processes on pharmaceutical products was investigated. Pharmaceutical substances such as clofibric acid, carbamazepine, diclofenac, ibuprofen and naproxen were found in the Montreal physicochemical primarytreated effluents at concentrations ranging from 13 to $3522 \mathrm{ng} / \mathrm{L}$. Most of the substances were eliminated at a rate lower than $10 \%$. Biological treatments (aerobic conditions) with activated sludge resulted in much better removal rates $(>50 \%$ ) for those studied substances. Interestingly, this type of process showed some selectivity with respect to the size and polarity of the removed substances; the smallest and most polar substances were removed at better rates, while the persistent carbamazepine (273-483 $\mathrm{ng} / \mathrm{L})$ and diclofenac $(52-68 \mathrm{ng} / \mathrm{L})$ were poorly removed. In the case of treatment by aerated lagoons, the most abundant substances were hydroxy-ibuprofen (339-3938 ng/L), naproxen (16-763 n/L) and carbamazepine (164-425 ng/L). To assess the impacts of all these contaminants on the environment and human health, we need to better understand the chemical and physical transformations occurring at the treatment plant and in the receiving waters.
\end{abstract}

Keywords: pharmaceuticals, treatment plant, fate, removal, wastewater. 


\section{Introduction}

The presence of pharmaceutical and personal-care products (PPCPs) in municipal wastewaters and many aquatic ecosystems raises growing concerns about environmental and human health [1,2]. Halling-Sørensen et al. [3] found that PPCPs and their metabolites are introduced into the environment via a number of routes, the primary one being the discharge of treated and untreated wastewater to rivers.

Nevertheless, Kümmerer [4] has explained that an important consideration when assessing the environmental fate of PPCPs is that, as a specific class compounds, they generally possess characteristics that make them different than conventional industrial chemical pollutants. Owing to their hydrophilicity and stability, PPCPs tend to remain in the aqueous phase and are not totally eliminated by sewage treatment plant (STP); as a consequence they and their metabolites are still frequently detected in surface waters [5]. Anti-inflammatory and anti-convulsive drugs are being detected in measurable quantities in municipal wastewaters (e.g., refs [6-8]).

Nowadays, certain major treatment plants are still using limited physicochemical processes that unfortunately generate unreliable data on organic contaminant removal efficiencies as for pharmaceutical substances. According to Gehr and Nicell [9], physicochemical treatment processes in particular feature higher values for water quality parameters than would be expected with biological treatments. Besides the improved biological quality of the treated wastewater, information on the removal of chemical contaminants like the ubiquitous pharmaceutical products found especially in poorly treated wastewaters is required. Such information is used to evaluate the sources of pharmaceuticals into the receiving environment, and therefore to assess the environmental risks related to effluent discharges with various wastewater treatment processes.

This paper describes the occurrence of target pharmaceuticals in municipal wastewaters once treated by different processes. The main objective of this study was to compare three different treatment plant types in order to determine their capacity to remove selected pharmaceutical residues from municipal wastewaters.

\section{Methods}

\subsection{Wastewater treatment}

Treatment processes investigated were of various types, from physicochemical to biological processes, as well as simple aerated lagoons. Information on visited treatment plants is given in Table 1.

The physicochemical wastewater treatment plant located in Montreal, Canada, is the largest one in North America. This major sewage treatment plant (STP) investigated, processes 1.3 million $\mathrm{m}^{3}$ of raw sewage daily (Table 1 ). The primary-treated wastewater results from both physical and chemical treatments; 
the latter is accomplished by the addition of flocculants agents such alum (10 $\mathrm{mg} / \mathrm{L})$ and $\mathrm{FeCl}_{3}(10-20 \mathrm{mg} / \mathrm{L})$ that removes suspended materials and associated contaminants. Municipal STP of Granby consists of mechanical pre-treatment (grid removal set-up and sand filtration), followed by a secondary treatment process involving the formation of aerobic activated sludge. Lastly, aerated lagoons are located in the cities of Chambly, St-Basile-le-Grand and Mascouche. For Montreal and Granby STPs, waters samples were taken as $24 \mathrm{~h}$ flowproportional composite samples from mechanical devices. Regarding the aerated lagoons, rapid "snap-shot" samples were taken around noon at each STP. Mean $\mathrm{pH}$ values for all visited STP ranged from 8.1 to 8.3 .

Table 1: $\quad$ Information on visited sewage treatment plants (STPs).

\begin{tabular}{|c|c|c|c|c|c|}
\hline STP & $\begin{array}{c}\text { Treatment } \\
\text { processes }\end{array}$ & Population & $\begin{array}{c}\text { Flow rate } \\
\left(\mathrm{m}^{3} / \mathrm{d}\right)\end{array}$ & $\begin{array}{c}* \mathrm{DBO}_{5} \\
(\mathrm{Kg} / \mathrm{d})\end{array}$ & $\begin{array}{c}* \mathrm{DOC} \\
(\mathrm{mg} / \mathrm{L})\end{array}$ \\
\hline Montreal & Physicochemical & $1,780,000$ & $1,300,000$ & 144,000 & 102 \\
Granby & Biological & 44,000 & 56,000 & 6,800 & 44 \\
$\begin{array}{c}\text { St-Basile-le- } \\
\text { Grand }\end{array}$ & $\begin{array}{c}\text { Aerated lagoon } \\
(8)\end{array}$ & 43,112 & 25,595 & 2,715 & $\mathrm{n} / \mathrm{a}$ \\
$\begin{array}{c}\text { Mascouche } \\
\text { Chambly }\end{array}$ & $\begin{array}{c}\text { Aerated lagoon } \\
(4)\end{array}$ & 42,320 & 18,836 & 2,308 & 35 \\
& $\begin{array}{c}\text { Aerated lagoon } \\
(4)\end{array}$ & 17,155 & 18,640 & 1,443 & $\mathrm{n} / \mathrm{a}$ \\
\hline
\end{tabular}

* Mean annual value. ( ) indicates number of aerated lagoons.

\subsection{Pharmaceutical sampling and analysis}

The PPCPs selected for the study are listed in Table 2 alongside their molecular weight (M.W.) and respective uses. Samples of treated and, in some cases, untreated effluents were taken three times (March 2005 to October 2006) directly at the plant and transported to the laboratory in Spartanburg ${ }^{\mathrm{TM}}$ stainless steel containers and stored in the dark at $4^{\circ} \mathrm{C}$ for less than 24 hours until the extraction step. Prior to extraction, each wastewater sample was filtered under a nitrogen flow from the Spartanburg ${ }^{\text {TM }}$ container through a 142-mm glass fiber filter $(0.7$ $\mu \mathrm{m})$ and then on a $90-\mathrm{mm} \mathrm{GF} / \mathrm{F}$ glass microfiber filter $(0.7 \mu \mathrm{m})$ with a fritted, all-glass filtration device and Celite 545 under tab vacuum. Pharmaceutical residues were then extracted from wastewater samples following the method of Lajeunesse and Gagnon [10]. Briefly, solid-phase extractions were performed with polymeric cartridges (Strata-X) before a derivation step with BSTFA $+10 \%$ TMCS in acetonitrile is completed. The derivatized extracts were analysed by a GC-MS/MS system (Trace GC Ultra - PolarisQ, Thermo Electron Corporation). The method's limit of detection (LOD) ranged from 1 to $18 \mathrm{ng} / \mathrm{L}$. 
Table 2: $\quad$ Selected PPCPs for the study.

\begin{tabular}{|c|c|c|}
\hline Compounds & M.W. $(\mathrm{g} / \mathrm{mol})$ & Use \\
\hline Salicylic acid & 138.1 & Analgesic (ASA metabolite) \\
\hline Clofibric acid & 214.6 & Lipid regulator (clofibrate metabolite) \\
\hline Ibuprofen & 206.3 & Anti-inflammatory \\
\hline 2-Hydroxy-ibuprofen & 222.3 & Anti-inflammatory (ibuprofen metabolite) \\
\hline Fenoprofen & 242.3 & Anti-inflammatory \\
\hline Naproxen & 230.3 & Anti-inflammatory \\
\hline Triclosan & 289.5 & Antibacterial \\
\hline Ketoprofen & 254.3 & Anti-inflammatory \\
\hline Carbamazepine & 236.1 & Anti-convulsive \\
\hline Diclofenac & 296.1 & Anti-inflammatory \\
\hline
\end{tabular}

\section{Results and discussion}

\subsection{Occurrence of pharmaceutical products in treated wastewater}

\subsubsection{Physicochemical-treatment}

The most abundant pharmaceuticals were found in physicochemical-treated effluents. Concentrations of the target pharmaceutical products in the primarytreated Montreal effluent ranged from $23 \mathrm{ng} / \mathrm{L}$ to $2556 \mathrm{ng} / \mathrm{L}$ (Fig. 1a). Salicylic acid, 2-hydroxy-ibuprofen, ibuprofen, and naproxen were most abundant $(>500$ $\mathrm{ng} / \mathrm{L})$; indeed, these substances seem to resist physicochemical wastewater treatment, which is relatively ineffective in removing pharmaceuticals in general at the plant [10-12].

\subsubsection{Biological treatment}

Compared to physicochemical treatment, concentrations of pharmaceutical substances were typically lower in biological-treated effluents (Fig. 1b). With the exception of the metabolite 2-hydroxy-ibuprofen, the highest concentration observed was for naproxen with a maximum concentration of $650 \mathrm{ng} / \mathrm{L}$. Relatively high concentration of 2-hydroxy-ibuprofen could be explained by the transformation of ibuprofen at the plant, and thus help to understand the low concentration (130 ng/L) observed for ibuprofen after treatment.

\subsubsection{Treatments by aerated lagoons}

Concentrations of pharmaceuticals measured in effluents from aerated lagoons were comparable, in several cases, to those from activated sludge (Fig. 1c). The metabolite 2-hydroxy-ibuprofen appeared in relatively high concentrations in comparison to its parent molecule ibuprofen. This observation could be explained by an extended aeration stage under bacterial activity, as reported by Lishman et al. [13]. Similar trends were observed with the biological process using activated sludge (Fig. 1b).

\subsection{Removal of pharmaceutical substances from municipal wastewater}

Figure 2 clearly shows low removal of pharmaceuticals in physicochemicaltreated effluents. Best removal efficiencies were about $30 \%$. No significant 
removal was even observed for salicylic acid and carbamazepine. As this type of treatment is based on accelerated (forced) flocculation of matter, sorption onto suspended particles does not appear to be of relevance to these types of polar substances. Due to their polar structures, Heberer [14] and Hirsch et al. [15] have observed that most PPCPs are not removed in any significant way by wastewater treatment.

a)

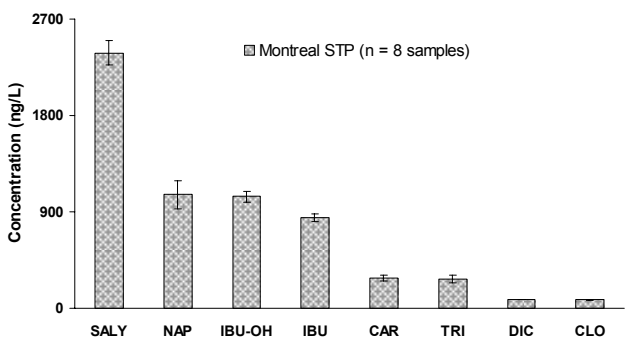

b)

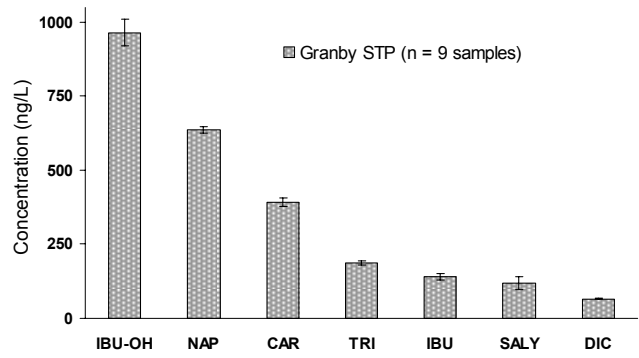

c)

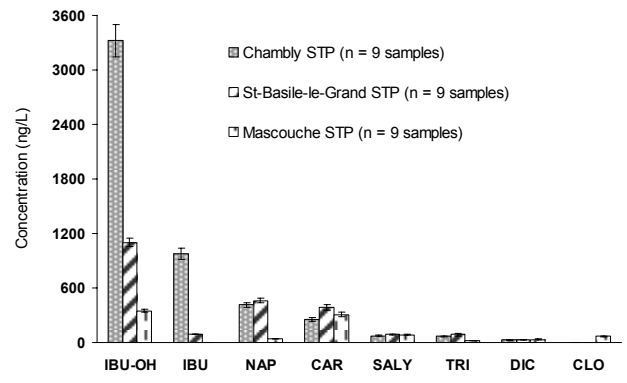

Figure 1: Concentrations in wastewater effluents after different treatment types: a) physico-chemical; b) activated sludge and c) aerated lagoons. SALY: salicylic acid; CLO: clofibric acid; IBU: ibuprofen; IBU-OH: 2-hydroxy-ibuprofen; NAP: naproxen; TRI: triclosan; CAR: carbamazepine; DIC: diclofenac. 
a)

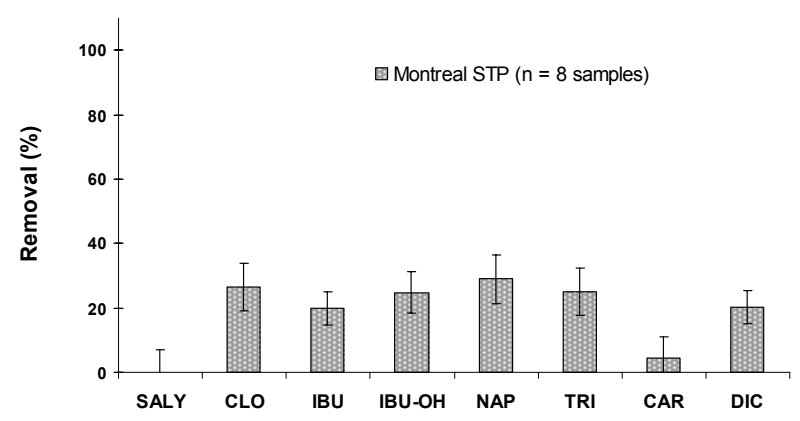

b)

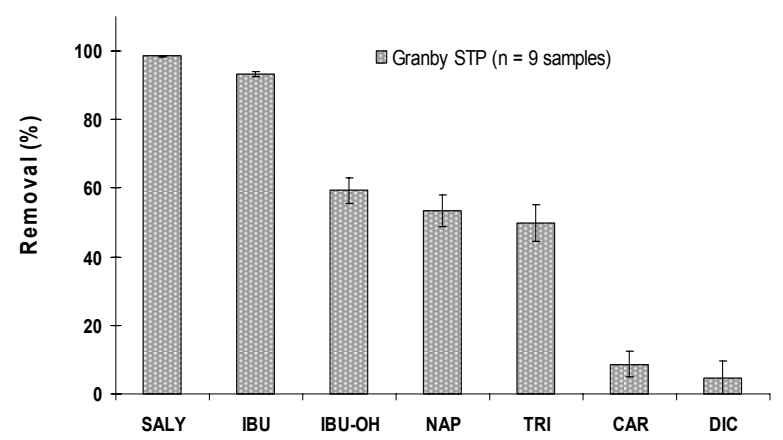

Figure 2: Removal of pharmaceuticals from a) physicochemical and b) biological wastewater treatment plants. SALY: salicylic acid; CLO: clofibric acid; IBU: ibuprofen; IBU-OH: 2-hydroxyibuprofen; NAP: naproxen; TRI: triclosan; CAR: carbamazepine; DIC: diclofenac.

Biological treatment with activated sludge was found to be the most efficient $(>50 \%)$ of the three treatment types investigated (Fig. 2b). Salicylic acid and ibuprofen were practically eliminated $(>95 \%)$. While most substances were highly affected by this type of treatment, carbamazebine and diclofenac remained slightly removed $(5-10 \%)$. Interestingly, this treatment seemed to indicate selectivity with respect to the size and polarity of the removed substances (Table 2). This observation could point out certain influence of inherent properties of the studied substances on their fate in wastewater treatment plants. Despite the reported persistence of carbamazepine by Clara et al. [16], and diclofenac by Lee et al. [17], the smallest molecules were typically more removed than the largest ones.

Treatments by aerated lagoons typically seemed to result in "mitigated" rates of removal efficiency for several studied substances (Fig. 1c). Despite it is practically impossible to sample the exact water mass upstream the plant (due to 
variable flows over long residence period (18 to 21 days)) for purpose of comparison between concentrations after and before treatment, wastewater treatment using lagoons cannot be entirely considered with respect to the resilience of all substances studied here. Although no removal efficiency rates were therefore reported for these "long residence time" treatment plants, the measured concentrations after treatment were in some cases not significantly lower than ones in effluents of comparable size and type (Granby). Removal rates could be expected be low especially for substances such as ibuprofen or carbamazepine which are either hydrophilic or persistent.

\subsection{Properties and removal of pharmaceuticals from wastewater}

Hence, as observed by several authors [6-8], the pharmaceuticals removal rate of acidic compounds such lipid regulator clofibric acid, non-steroidal antiinflammatory drugs (NSAIDs), and persistent neutral anti-convulsive carbamazepine, is rather low, because their high water solubility and poor degradability. In a more optimistic scenario, some of these emerging substances undergo major transformation to unknown metabolites at the sewage treatment plant after biological and chemical degradations.

As reported by Kümmerer [4], a major factor influencing the efficiency of pollutant removal from raw sewage is their ability to interact with solid particles, both natural (clay, sediments, microorganisms) or added to the medium (active carbon, coagulants), because this facilitates their removal by physicochemical (precipitation, flotation) or biological processes (biodegradation with activated sludge).

Among the studied substances, the heteroatom content and the chemical functionalities revealed by the hydroxyl and carboxylic acid moieties makes them polar, ionisable molecules with physicochemical properties that could largely explained their occurrence by our group [10] and other Canadian researchers $[17,18]$ in sewage treatment plants. Their reported properties, coupled with trace quantities, create unique challenges for both removal processes and analytical detection.

\section{Conclusion}

The results of the present study clearly point out quite low removal efficiency of the studied pharmaceuticals from physico-chemical treatments. Much higher removal efficiencies were observed at aerated lagoons and even better with biological processes as activated sludge. The efficiency was significantly influenced by the molecular size of the substances removed or not. Certain substances such as carbamazepine, diclofenac and hydroxy-ibuprofen typically remain persistent in the investigated treatment plants. 


\section{Acknowledgements}

The authors are indebted to the staff of the Montreal, Chambly, Granby, StBasile-le-Grand and Mascouche STPs for their technical assistance. This work was funded by the St. Lawrence Action Plan.

\section{References}

[1] Daughton, C.G. \& Ternes, T.A. Pharmaceuticals and personal care products in the environment: agents of subtle change? Environ. Health Perspect., 107 (suppl. 6), pp. 907-938, 1999.

[2] Kolpin, D.W., Furlong, E.T., Meyer, M.T., Thurman, E.M., Zaugg, S.D., Barber, L.B., Buxton, H.T. Pharmaceuticals, hormones, and other organic wastewater contaminants in U.S. stream, 1999-2000: a national reconnaissance. Environ. Sci. Technol., 36, pp. 1202-1211, 2002.

[3] Halling-Sørensen, B., Nors Nielsen, S., Lanzky, P.F., Ingerslev, F., Holten Lutzhoft, H.C., Jorgensen, S.E. Occurrence, fate and effects of pharmaceutical substances in the environment - a review. Chemosphere, 36, pp. 357-393, 1998.

[4] Kümmerer, K. (Eds). Pharmaceuticals in the Environment $2^{\text {nd }}$ edition, Springer: Berlin Heidelberg New-York, 2004.

[5] Gentili, A. Determination of non-steroidal anti-inflammatory drugs in environmental samples by chromatographic and electrophoretic techniques. Anal. Bioanal. Chem., 387, pp. 1185-1202, 2007.

[6] Heberer, T., Dünnbier, U., Reilich, C., Stan, H.J. Detection of drugs and drug metabolites in ground water samples of a drinking water treatment plant. Fresen. Environ. Bull., 6, pp. 438-443, 1997.

[7] Ternes, T.A. Occurrence of drugs in German sewage treatment plants and rivers. Water Res., 32, pp. 3245-3260, 1998.

[8] O'Brien, E. \& Dietrich, D.R. Hindsight rather than foresight: reality versus the EU draft guideline on pharmaceuticals in the environment. Trends Biotechnol., 22 (7), pp. 327-330, 2004.

[9] Gehr R. \& Nicell J. Pilot studies and assessment of downstream effects of UV and ozone disinfection of a physicochemical wastewater. Wat. Qual. Res. J. Canada, 31, pp. 263-281, 1996.

[10] Lajeunesse, A. \& Gagnon, C. Determination of acidic pharmaceuticals and carbamazepine in roughly treated sewage by solid phase extraction and gas chromatography-tandem mass spectrometry. Intern. J. Environ. Anal. Chem., 87 (8), pp. 565-578, 2007.

[11] Segura, P.A., García-Ac, A., Lajeunesse, A., Ghosh, D., Gagnon, C., Sauvé, S. Determination of six anti-infectives in wastewater using tandem solid-phase extraction and liquid chromatography-tandem mass spectrometry. J. Environ. Monit., 9, pp. 307-313, 2007,

[12] Snyder S.A, Westerhoff P. Yoon Y, Sedlak D.L. Pharmaceuticals, personal care products, and endocrine disruptors in water: Implication for the water industry. Environ. Eng. Sci. 20, pp. 449-469, 2003. 
[13] Lishman L, Smyth SA, Sarafin K, Kleywegt S, Toito J, Peart T, Lee B, Servos M, Beland M, Seto $P$. Occurrence and reductions of pharmaceuticals and personal care products and estrogens by municipal wastewater treatment plants in Ontario, Canada. Sci. Tot. Environ. 367, pp. 544-558, 2006.

[14] Heberer T. Occurrence, fate, and removal of pharmaceutical residues in the aquatic environment: a review of recent research data. Toxicol. Lett., 131 (1-2), pp. 5-17, 2002.

[15] Hirsch, R, Ternes, T., Haberer, K. Occurrence of antibiotics in the aquatic environment. Sci. Tot. Env., 225, pp, 109-118, 1999.

[16] Clara, M., Strenn, B., Kreuzinger, N. Carbamazepine as a possible anthropogenic marker in the aquatic environment: investigations on the behaviour of carbamazepine in wastewater treatment and during groundwater infiltration. Water Res., 38, pp. 947-954, 2004.

[17] Lee, H.B., Sarafin, K., Peart, T.E., Svoboda, M.L. Acidic pharmaceuticals in sewage - Methodology, stability test, occurrence, and removal from Ontario samples. Water Qual. Res. J. Canada, 38, pp. 667-682, 2003.

[18] Miao, X.S., Koenig, B.G., Metcalfe, C.D. Analysis of acidic drugs in the effluents of sewage treatment plants using liquid chromatographyelectrospray ionization tandem mass spectrometry. J. Chromatogr. A., 952, pp. 139-147, 2002. 